\title{
Territorio mutual: una lectura del proceso de trasformación territorial desde la alteridad de la comunidad LGBTI víctima del desplazamiento forzado en el Quindío*
}

DOI: https://doi.org/10.18046/recs.i32.3532

\begin{abstract}
Mutual Territory: A Reading of Territory Transformation from the Point of View of the Otherness of LGBT Victims of Forced Displacement in Department of Quindio, Colombia
\end{abstract}

Carlos Alberto Castaño-Aguirre**

Universidad de San Buenaventura (Medellín, Colombia)

\footnotetext{
* Este artículo es producto de la investigación denominada "Lectura del proceso de trasformación territorial desde la alteridad de la comunidad LGBTI víctimas del desplazamiento forzado en el departamento del Quindío", financiada por la Universidad de San Buenaventura (Colombia), con una duración de un año. Artículo de investigación recibido el 15.04.2019 y aceptado el 07.01.2020.

** Docente investigador de la Facultad de Artes Integradas, Universidad de San Buenaventura (Colombia). Correo electrónico: carlos.castano17@tau.usbmed.edu.co ORCID: https://orcid.org/oooo-ooo3-1421-1127
} 


\section{Cómo citar/How to cite}

Castaño-Aguirre, Carlos Alberto (2020). Territorio mutual: una lectura del proceso de trasformación territorial desde la alteridad de la comunidad LGBTI víctima del desplazamiento forzado en el Quindío. Revista CS, 32, 221-247. https://doi.org/10.18046/recs.i32.3532 


\section{Resumen}

Las personas del grupo social LGBTI víctimas del desplazamiento forzado causado por el conflicto social y armado en Colombia han llegado a nuevos territorios receptores que les permiten reconstruir su vida en él, posibilitando sus capacidades y libertades; a su vez, este territorio es transformado por ellos, por medio de sus saberes y sentires, en una relación de mutualismo donde ambos contribuyen al desarrollo territorial. El presente artículo tiene como objetivo interpretar el proceso de trasformación territorial desde la alteridad de la comunidad LGBTI víctima del desplazamiento forzado en el departamento del Quindío, para lo cual se plantea una investigación interpretativa con un enfoque histórico hermenéutico desde las categorías de la proxémica (el espacio íntimo, personal y público), así como la comprensión mediante mapeo social de la relación cuerpo-territorio de una comunidad históricamente invisibilizada y revictimizada por su orientación sexual, identidad y expresión de género.

\section{PALABRAS CLAVE:}

territorio, mutualismo, alteridad, desplazamiento, comunidad LGBTI

Thousands of LGBTI people have been victims of the forced displacement caused by the social and armed conflict in Colombia. Those people have arrived at new territories and rebuilt their lives, enhancing their freedom and abilities. At the same time, they transform this territory with their feelings and knowledge. This article aims at understanding the transformation of the territory from the alterity of the LGBTI victims of forced displacement in the department of Quindío, Colombia. We carried out an interpretative research with a hermeneutic approach based on the proxemics categories (intimate, personal, and public spaces), as well as a comprehensive review through social mapping of the body-territory relationship of this invisible and revictimized community because of its sexual orientation, gender identity, and gender expression.

\section{KEYWORDS:}

Territory, Mutualism, Alterity, Forced Displacement, LGBTI Community 

....No tenía nombre ese planeta -no para nosotros, en la Tierra, pues quedaba muy lejos y nadie nunca lo había nombrado-. De ahí su importancia, decía el: que a pesar de que existiera y supiéramos que existía, no tuviera un nombre.

Era un mundo huérfano, sin sol, y la noche, portanto, eraperpetua...

Giuseppe Caputo (2016)

\section{Introducción}

Una de las problemáticas en torno a los temas del conflicto social y armado en Colombia y las comunidades LGBTI es el desconocimiento del impacto cuantitativo de víctimas pertenecientes a esta comunidad. De acuerdo al Centro Nacional de Memoria Histórica (CNMH, 2015: 40),

una constante en los esfuerzos por describir los efectos del conflicto armado en quienes se apartan de las normas de género y sexualidad es la dificultad para ofrecer cifras, pues, en efecto, conseguir estas cifras enfrenta múltiples obstáculos en distintos niveles.

Por una parte, está la invisibilización y no denuncia del acto violento como mecanismo de protección de la víctima, la cual normalmente ha vivenciado múltiples formas de violencia y exclusión en su cotidianidad, la familia, la comunidad, la escuela, entre otras, que lleva a que su afectación por el conflicto social y armado no sea percibida como disímil a la continua violencia que ha marcado la vida de estas personas. Por otro lugar, se localiza la institucionalidad, que en su mayoría no se encuentra capacitada para la atención de víctimas con orientaciones sexuales e identidades de género que se apartan de la norma, lo que conlleva una inadecuada atención y un sesgo en la información encontrada.

De acuerdo al Registro Único de Victimas (RUV), con corte en 2018, se han registrado un total de 2235 víctimas que se identifican como pertenecientes a la comunidad LGBTI, y 61500 que no informan el género al que corresponden, evidenciando el temor al reconocimiento como miembro de este grupo, así como la limitada cercanía a las verdaderas cifras de violencia que tiene el Estado, por lo menos las que corresponden a dicha comunidad (Unidad para la atención y reparación integral a las víctimas, 2018).

La visibilidad en los territorios por parte de integrantes de la comunidad LGBTI ha intensificado su vulnerabilidad y puesto en riesgo su integridad, según Colombia Diversa y Caribe Afirmativo (2018: 66): 
La visibilidad es un riesgo no solamente para las defensoras y defensores. Otros de los casos de amenazas contra personas LGBT en 2017 fueron contra parejas del mismo sexo o grupos de personas LGBT que, sin ser activistas ni integrantes de organizaciones sociales, fueron amenazados por el simple hecho de ser visibles en su barrio, su municipio o su región.

A pesar de las múltiples violencias propiciadas por una sociedad heteronormativa, que han obligado al no reconocimiento e invisibilización de una comunidad (ver Figura 1), podemos identificar en los territorios procesos de transformación y mutación que se potencializan con la génesis de un morar. El departamento del Quindío ha sido receptor y caldo de cultivo para este nuevo morar, y en él se evidencian relaciones violentas que siguen intensificando el dolor de quienes han sido desterrados. "En Armenia, por ejemplo, paramilitares amenazaron a una mujer lesbiana víctima del conflicto y defensora de derechos humanos, a quien acusaron de ser una 'guerrillera' y amenazaron para que abandonara su trabajo con la Mesa Departamental de Víctimas del Quindío" (Colombia Diversa; Caribe Afirmativo, 2018: 66).

FIGURA 1 Imagen dialéctica sobre la violencia y la invisibilización LGBTI

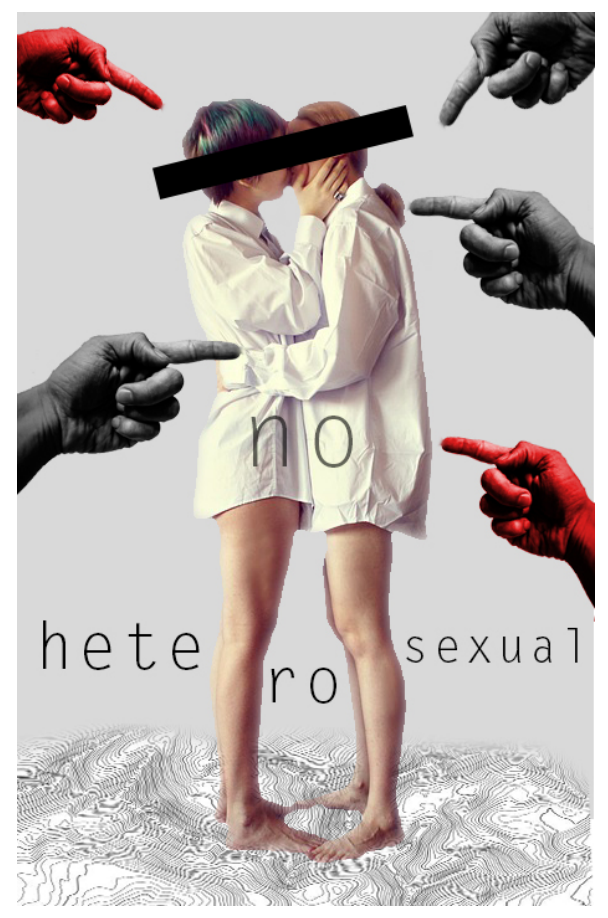

Fuente: elaboración propia. 
El conflicto social y armado en Colombia ha generado múltiples fenómenos y afectaciones en el territorio nacional. Para el departamento del Quindío, una de las afectaciones más reconocidas es la influencia del desplazamiento poblacional de víctimas de la violencia y el conflicto. De acuerdo a datos de la Red Nacional de Información (2018), en el departamento, en los últimos 5 años, se han reportado 5600 personas trasladadas como consecuencia del conflicto social y armado. Solo hasta 1995 el Estado colombiano hizo reconocimiento del desplazamiento como fenómeno importante y con graves consecuencias sociales, lo cual se hacía visible dentro de las poblaciones; para aquel año, se estimaba que el desplazamiento interno del país por causas del conflicto era de 600 ooo personas, las cuales migraron a los centros urbanos en condiciones de vulnerabilidad social (Rodrígues, 2013).

Dentro de las víctimas del conflicto, las personas de la comunidad LGBTI han sido unas de las más afectadas, aunque los patrones culturales discriminatorios no hacen posible conocer en su totalidad la magnitud de la problemática del enfoque de género en el conflicto social y armado colombiano, pues muchas personas desconocen su propia condición de víctimas o temen hacer las denuncias ante un Estado incapaz de garantizarles la dignidad, favoreciendo así la impunidad y la invisibilización de estas víctimas. Para el CNMH (2014: 107),

la poca información sobre victimizaciones de esta población en el marco del conflicto armado da cuenta de la ocurrencia de hechos de desplazamiento por distintas causas como las amenazas directas o el riesgo de reclutamiento, la violencia sexual, las conminaciones en contextos de control social, castigos ejemplarizantes y públicos, y las masacres, asesinatos selectivos y/o ejemplarizantes de gays, lesbianas y transgeneristas.

El desplazamiento es el resultado del temor por parte de integrantes de estas comunidades a ser reclutados o violentados por amenazas directas de los actores del conflicto, donde el victimario busca castigar a las personas por su identidad de género, expresión u orientación sexual, para reforzar los estereotipos de género con respecto a lo masculino y femenino.

De acuerdo a los principios orientadores del acuerdo entre el Gobierno de Colombia y la guerrilla de las FARC (2016:79), se plantea un enfoque territorial y diferencial:

En el marco del fin del conflicto y la construcción de una paz estable y duradera, las medidas de seguridad que se adopten deben tener un enfoque territorial y diferencial que tenga en cuenta las diferentes amenazas, particularidades y experiencias de las personas en su diversidad, de las comunidades y los territorios, con el fin de poner en marcha los planes y programas de construcción de paz y dar garantías a la población. 
Lo anterior evidencia que la condición de ser diferente es un factor que implicó la intensificación del conflicto y la importancia de abordarse de manera concienzuda, favoreciendo a las comunidades afectadas y a quienes padecieron hechos victimizantes por su identidad, expresión de género u orientación sexual.

Igualmente, la legislación colombiana, en búsqueda de satisfacer las necesidades y garantizar el ejercicio efectivo de los derechos de las personas de sectores sociales LGBTI, y entendiendo que han sido víctimas de discriminación y violencia estructural y cultural, publicó el Decreto 756 de 2018, el cual tiene como objeto "adoptar la política pública que tiene por objeto la promoción y garantía del ejercicio efectivo de los derechos de las personas que hacen parte de los sectores sociales LGBTI y de personas con orientaciones sexuales e identidades de genero diversas" (Art. 2.4.4.2.1.1), reconociendo un sector que ha tenido importantes contribuciones en la construcción de país, pero que aún sigue teniendo limitantes en el libre desarrollo de sus capacidades y libertades.

El desplazamiento implica el abandono y la búsqueda de un nuevo lugar, normalmente a ciudades donde se crea un imaginario de una posible mejora de la calidad de vida, estos territorios urbanos tienen ya unas dinámicas sociales y culturales marcadas, una forma de coexistencia que también se ve modificada por el arribo de los nuevos moradores, una hibridación cultural que surge de la trasformación del territorio, de sus dinámicas sociales construidas entre quienes llegan y quienes han estado allí, el destierro y la génesis de un morar.

La comprensión del modo adaptativo y cómo la comunidad LGBTI ha apropiado un territorio, dándole significado, experiencia y transformación física a un lugar, permite un acercamiento al papel de la misma en el desarrollo territorial; la inclusión de una comunidad históricamente segregada no solo por su identidad de género diverso, sino también por su condición de víctima en un nuevo lugar de arribo potencializa las capacidades de los habitantes de un lugar y permite el aprovechamiento de la multiplicidad de talentos para el desarrollo como humanidad.

\section{Estado de la cuestión}

De acuerdo a Colombia Diversa (2017: 29),

las investigaciones sobre la violencia en el conflicto armado contra las personas LGBT han coincidido en que los mecanismos de control social y de imposición de normas de conducta y de resolución de conflictos de los actores armados se alimentaron de los contextos de discriminaciones sociales preexistentes hacia las poblaciones vulnerables e históricamente discriminadas. 
Los sujetos que históricamente han sido vulnerados en sus derechos, como es el caso de las personas LGBTI, las mujeres, las etnias, entre otros, evidencian la manera en que el conflicto recrudece su situación de desigualdad, invisibilizando su sufrimiento y perpetuando el silencio ante la violación de su dignidad. La desigualdad y la violencia sexual tienen raíces históricas que se han apoyado en ideologías de patriarcado y en el estereotipo de la masculinidad y la feminidad. Al respecto, Pulecio (2015:36), en su investigación sobre los lenguajes violentos dirigidos a jóvenes LGBTI, establece que

ser LGBTQ en Colombia, como en cualquier país en donde históricamente predomine la heterosexualidad obligatoria, es saber qué es ser injuriado, ofendido e insultado. Además, ser estudiante LGBTQ es saber que, probablemente, en la escuela no habrá espacio para sus afectos: ni en las clases que recibe, ni en las preguntas que hace ni con las personas con las que comparte su vida; no de forma plena, no al menos sin llamar la atención.

El ser miembro del grupo social LGBTI intensifica los hechos victimizantes, la violencia hacia este grupo no solo ha estado relacionada con la violencia directa causada en el conflicto social y armado en Colombia, sino con toda una organización de la sociedad en la cual se evidencia una violencia estructural y cultural. Es necesario tener en cuenta la complejidad del concepto de violencia, en especial para las ciencias sociales, por la ambigüedad que implica el mismo. Según Galtung (2016:149), este concepto se direcciona a la violencia cultural, la cual define como

aquellos aspectos de la cultura, la esfera simbólica de nuestra existencia-materializado en la religión y la ideología, en el lenguaje y el arte, en la ciencia empírica y la ciencia formal (la lógica, las matemáticas) - que puede ser utilizada para justificar o legitimar la violencia directa o la violencia estructural.

Esta violencia cultural procede de la imposición de unos valores o pautas culturales que niegan la diversidad cultural y legitiman el uso de la fuerza como forma de resolver los conflictos. Partiendo de este concepto, se plantea que, inmersa en una violencia cultural, podemos encontrar tanto la violencia directa como la violencia estructural; una cultura de violencia permite la aparición de toda expresión de la misma.

Por su parte, la violencia estructural que procede de las estructuras sociales, políticas y económicas opresivas -impidiendo que las personas se desarrollen en toda su potencialidad-es también identificada dentro del género diverso. El laboratorio experimental de performance de la Fundación Waja (2012), con apoyo de la Universidad Jorge Tadeo Lozano, planteó que ser una mujer trans implica poca posibilidad 
de ingresar al mercado laboral, problemas psicológicos, desórdenes en el sistema nervioso, perdida de amistades y lazos familiares, además de los costos que conlleva la realización de procedimientos seguros en la construcción de su género, poniendo así en evidencia las problemáticas que implica ser una persona trans en Colombia. De acuerdo con Cardona Cuervo (2016: 93),

los derechos del grupo social transgénero, como un elemento de la comunidad LGTBI, se deben tipificar bajo el concepto de "Derechos Sociales Fundamentales" los cuales implican abstenciones y acciones por parte del Estado y los particulares, para trascender del mero reconocimiento de su identidad y desplegar acciones conducentes a afirmar su dignidad humana.

El grupo social de las personas LGBTI es altamente vulnerado en cuanto a sus derechos laborales, sociales y culturales; una problemática que radica en la discriminación generalizada y el no reconocimiento de su proceso de construcción de género y orientación sexual, tanto desde el mismo Estado como de la sociedad en general.

En el marco del plan de desarrollo del departamento del Quindío (2016-2019), se establecieron las condiciones necesarias para la construcción de paz en el territorio a través de cinco componentes, dentro de los cuales se encuentra la equidad social:

Gracias al enfoque integral de los Objetivos de Desarrollo Sostenible, se profundizará en la inclusión de los sectores que han sido más discriminados o desprotegidos, para fortalecer su atención, actuación y participación. Se trata fundamentalmente de crear condiciones sociales, económicas y culturales para el respeto hacia las diferentes confesiones religiosas, las personas LGBTI, las mujeres y las niñas, los discapacitados, la población afrocolombiana y las víctimas del conflicto, entre otras. Se trabajará en la generación de espacios pacíficos de desenvolvimiento que les permita acceder en condiciones de igualdad y con enfoque diferencial, a la misma calidad a bienes y servicios pero, sobre todo, a la garantía y respeto por sus derechos. (Gobernación del Quindío, 2016: 224)

Evidenciando la necesidad de reconocer la diferencia y cómo esta ha sido parte del Quindío, construyéndolo y permitiendo que este se proyecte como un territorio de paz e igualdad, un departamento que se ha convertido en receptor de víctimas del desplazamiento forzado. Para Henao Delgado (1999: 72),

al nomadismo que se inicia con el hecho del desplazamiento le va emergiendo un modo de vivir y pensar, un conjunto de creencias y valores, de conductas y hábitos, que van a terminar configurando un nuevo producto social y humano que pudiéramos llamar subcultura de desplazado. 
Esta construcción social y humana llamada subcultura de desplazado es la relación híbrida entre el territorio existente y los nuevos habitantes, involucrando el proceso adaptativo cultural. La naturaleza nos expone ejemplos de armónicas relaciones de reciprocidad e intercambio, las cuales nos permiten hacer analogías entre el territorio y quienes lo habitan, "por ejemplo, las abejas y las orquídeas son especies diametralmente distintas, que sobreviven y se reproducen gracias al mutualismo" (Ana González expone..., 2016). El mutualismo es el beneficio y el soporte de vida para el desterrado, a cambio de la transformación del territorio físico, social y cultural que se habita.

Los territorios mutuales permiten la interculturidad, el comprendernos como colectivo diverso, según Dietz (2017: 203),

la pluralidad de los mundos de vida, moldeados como un todo autorreferencial que provee de significado a sus miembros, requiere de una pluralización de las pautas de comprensión. Las posibilidades de la comprensión intercultural, que busca traducir entre estos tipos de mundos de vida, no sólo dependen de las competencias y las habilidades lingüísticas, tal como lo sugiere la comunicación intercultural, sino también del desarrollo de diálogos reflexivos y autorreflexivos.

Los estudios hermenéuticos permiten hacer un acercamiento a las realidades desde la diferencia, buscan la construcción de sentido a partir de contextos y su comprensión histórica, los saberes y emociones propios de la cotidianidad que aprueban la reflexión acerca de quienes no son escuchados, de quienes han sido segregados por discriminación, estigmatización, racismo, sexismo o clasismo, entre otras formas de marginalización.

\section{Marco teórico}

El conflicto social y armado colombiano, de acuerdo a Smith (2002:3), puede definirse "como confrontaciones abiertas y armadas entre dos o más partes centralmente organizadas, con continuidad de enfrentamientos, y en disputas sobre el poder gubernamental y territorio". Estas confrontaciones encuentran su causa en las condiciones de pobreza económica, los sistemas políticos represivos, la degradación de los recursos renovables y la diversidad étnica, que si bien no es una causal de conflicto, en muchos casos los actores tienden a identificarse con una etnia en particular. Este conflicto es el escenario en el que se desarrollan las múltiples formas de violencia hacia las comunidades LGBTI, donde tanto los actores legales como ilegales han intensificado el estado de discriminación y la invisibilización de las víctimas. 
Es precisamente en el marco del conflicto social y armado donde se evidencian diferentes fenómenos, entre los cuales se resalta el desplazamiento forzado. De acuerdo al registro único de víctimas, en 2018 las personas afectadas ascendían a 7434 999. El concepto de desplazamiento, abordado desde la perspectiva social y política de González (2006: 43), se establece como:

El desplazamiento se relaciona con un sistema político estructurado históricamente sobre la exclusión de las mayorías pobres de los ámbitos de decisión económica y política y de sus beneficios (aunque formalmente se trate de la democracia más antigua de América Latina), y se sustenta en una visión excluyente del “otro", típica en la historia de Colombia.

Se plantea, desde este enfoque, la exclusión y el desconocimiento del otro como elementos estrechamente relacionados con el fenómeno del desplazamiento en Colombia, donde los desplazados son generalmente esas personas a las cuales el Estado no pudo garantizarles la seguridad, y se enfrentan a situaciones que afectan su calidad de vida, personas pobres económicamente, y minorías como los afrocolombianos y las personas LGBTI.

El desplazamiento implica el estudio del territorio, la relación entre quien llega $\mathrm{y}$, a través de su forma de relación con su entorno, con la cultura, transforma y construye nuevas territorialidades. Para Molina (2018: 6):

El territorio constituye una categoría densa que presupone un espacio geográfico apropiado, y esa apropiación -territorialización- crea las condiciones para la construcción de identidades -territorialidades-, las cuales están inscritas en procesos históricos, siendo por eso dinámicas y cambiantes, materializando en cada momento un determinado orden, una determinada configuración territorial, una topología social.

Ocultas tras las morfologías territoriales, están escondidas las maneras humanas de satisfacer sus necesidades; en la creación territorial aparecen pirámides invisibles de necesidades que se pueden suponer, pero que no se ven. Lo visible no da clave de lo invisible y, sin embargo, el territorio, como resultado de la compleja relación eco-bio-antropológica, es la expresión más material de las necesidades humanas. Como motores de la manipulación de las grandes lógicas, las necesidades obligan a los humanos a proyectar su trabajo en el material y a movilizar las fuentes disponibles de energía e información acumulada (Raffestin, 2012).

Son las dinámicas sociales del habitar las que posibilitan y les dan sentido a los territorios, una construcción de identidad a través de la memoria, de los sucesos y experiencias que marcan, que quedan en el recuerdo; los territorios generan un 
sentir al individuo, pero, a su vez, se da un proceso de relevo de información que inicia la producción colectiva de imaginarios y de emociones comunes, esto permite adhesión y disgregación, define la particularidad y la diferencia, la alteridad. El miedo de reconocer al otro intensifica el riesgo y la vulnerabilidad de las personas con menos poder político y económico, la alteridad implica el poner en valor al otro, al diferente, al excluido. Para Hidalgo (2006: 10), la alteridad conlleva

momentos que no se excluyen, sino que se complementan en una sincronía ilimitada. Las diferencias, los contrarios aparecen y se disuelven al mismo tiempo. No hay absolutos, sino posibilidades. Lo diferente, la otredad son momentos de un discurrir permanente, de un fluir intemporal e imprevisible. Un fluir donde los límites entre lo propio y lo extraño, lo mismo y lo diferente, no son estados permanentes y fijos, sino experiencias relativas en constante movimiento.

La alteridad implica la diferencia y la construcción a partir de ella, así como la constante dinámica y movimiento que surgen de las relaciones diarias con el otro, que tienen lugar en una espacialidad, y sumando espacio y acción humanas dan paso a la territorialidad, la cual, de acuerdo a Bustos y Molina (2012: 2), está dada "en términos de reconocer el significado de las dinámicas culturales que en el interactúan reconociéndolo como una construcción social que da significado al espacio geográfico en términos de su representación cultura”. Por su parte, Eito y Gómez (2013: 15) afirman que:

El concepto de comunidad tiene hoy, para los Trabajadores Sociales especialmente, un valor de motor ideológico, de cambio, de participación, de contar con las personas, de mejorar, componer o construir relaciones, de fortalecer el tejido social, de cambio social y búsqueda de una sociedad más cohesionada y más justa.

Desde la perspectiva del fortalecimiento del tejido social, la comunidad se establece como la participación activa de sus integrantes para el empoderamiento de sus procesos habitacionales y la satisfacción de las necesidades del colectivo. La comunidad y el territorio generan mutualismo, una relación armónica que permite sobrevivir al ser social y al medio. Para Molina y Calzadilla (2010: 4),

el mutualismo social [es] asumido como la combinación de elementos que son disímiles uno del otro, para crear nuevas formas y hacer cosas que jamás se podrían efectuar por sí solo. En cuanto a la diversidad es la multitud de características de los organismos en su conjunto y su relación con el medio; y la complejidad entendida como la emergencia de procesos multidimensionales, multirreferenciales e interactivos con componentes de aleatoriedad e incertidumbre. 
El mutualismo implica la construcción y emergencia de nuevos territorios, el territorio se dinamiza, muta, mientras el individuo se beneficia y sobrevive de sus recursos, esto en un contexto espacial, el lugar de la acción del ser, el territorio alterado. Por su parte, Edward Hall (como se citó en Ardelean, 2001: 7)

\begin{abstract}
define la proxémica como las observaciones y teorías interrelacionadas sobre el uso humano del espacio visto como una elaboración especializada de la cultura. En otras palabras, la proxémica se refiere al estudio de la relación entre el hombre y la dimensión espacial de su ambiente, pero también al patrón de conducta inter-humana en la matriz espacial.
\end{abstract}

Dentro de la proxémica, se pueden identificar tres espacios en correspondencia con las distancias del individuo y sus relaciones de introspección e interacción: el espacio íntimo (o a $50 \mathrm{~cm}$ ), el espacio personal ( $50 \mathrm{~cm}$ a 3,5 $\mathrm{m}$ ) y el espacio público (más de 3,5 m), cada uno de ellos se trasforma y dinamiza con la percepción del individuo, con su sentir y su identidad, una transformación territorial que le permite al ser desarrollar sus capacidades, un morar en una relación mutual -territorio y ser-lleno de constantes metamorfosis y alteraciones de sus esencias duales.

\title{
Metodología
}

La investigación es de tipo interpretativa, donde se busca comprender el proceso de trasformación territorial desde la alteridad de la comunidad LGBTI víctima del desplazamiento forzado en el departamento del Quindío. Partiendo del concepto de la proxémica espacial, identificar las trasformaciones/mutaciones resultado de las relaciones mutuales entre el ser y el espacio físico-social habitado, el espacio íntimo, el personal y el público. Es una investigación cualitativa desde un enfoque histórico hermenéutico. Para Ángel Pérez (2011: 18), "la pretensión hermenéutica es una experiencia histórica más que un ejercicio contemplativo de saber. Es un comprenderse como ser histórico en el acontecer histórico", un diálogo que busca reconocer los diferentes actores del conflicto social y armado en Colombia, sus percepciones particulares y su forma de habitar y relacionarse con el territorio. Por su parte, Alvarado, Ospina y Sánchez (2016: 993) afirman que:

La realidad de la investigación social es mixta; ello hace que la hermenéutica como disciplina se desarrolle en el diálogo que la constituye. Aquí, vale decir que el diálogo no debe ser entendido como la resolución de la diferencia, sino como su reconocimiento, como razón de ser de la condición humana. 
En la investigación cualitativa, hay una "descripción constante de la realidad o problema encontrado cruzado con conceptos, más temáticas y preguntas que nos realizamos a todo ello emerge el objeto de sabery/o pregunta problema" (Jiménez, 2017:4).

Asimismo, la hermenéutica permite una comprensión de la otredad desde la heterogeneidad del ser, posibilitando la visibilización de los actores y víctimas del desplazamiento forzado en Colombia. La investigación está compuesta de cuatro ciclos hermenéuticos:

1. Ciclo hermenéutico 1: reconocer la transformación del espacio corporal e íntimo de la comunidad LGBTI víctima del desplazamiento forzado en el nuevo morar.

- Observación de campo

- Cartografía social

- Relato (entrevista)

2. Ciclo hermenéutico 2: reconocer el proceso habitacional desde el espacio personal apropiado por la comunidad LGBTI víctima del desplazamiento forzado en el departamento del Quindío.

- Observación de campo

- Cartografía social

- Relato (entrevista)

3. Ciclo hermenéutico 3: identificar las relaciones mutuales en el espacio público desde la alteridad de la comunidad LGBTI víctima del desplazamiento forzado en el departamento del Quindío.

- Observación de campo

- Cartografía social

- Relato (entrevista)

4. Ciclo hermenéutico 4: interpretar el proceso de trasformación territorial desde la alteridad de la comunidad LGBTI víctima del desplazamiento forzado en el departamento del Quindío.

- Matriz de categorías desde la proxémica: espacio íntimo, personal y público.

La unidad de análisis son las relaciones mutuales evidenciadas en la transformación territorial desde el espacio íntimo, personal y público. La unidad de trabajo son los habitantes del departamento del Quindío miembros de la comunidad LGBTI y víctimas del desplazamiento forzado, quienes han modificado el territorio desde su habitar. 
Se desarrollan tres talleres con personas del grupo social LGBTI víctimas del desplazamiento forzado en el conflicto social y armado en Colombia, donde el departamento del Quindío fuera el territorio receptor. El primer taller es aplicado a mujeres transgénero; el segundo, a hombres gais, y un tercer taller, a mujeres cisgénero lesbianas, categorías con las cuales los participantes se autorreconocían. Los talleres incluyeron una entrevista semiestructurada que recolectara los relatos y las dinámicas de la transformación del territorio, apropiación por parte de quienes fueron desplazados, y el mapeo cuerpo-territorio donde se relacionara el territorio habitado con el territorio corporal a través de la ubicación de los componentes representativos desde los sentires de los participantes.

TABLA 1 Objetivos e instrumentos de recolección de información

\section{Objetivo \\ Instrumentos \\ ¿A quién?}

Reconocer la transformación del espacio corporal e íntimo de la comunidad LGBTI víctima del desplazamiento forzado en el nuevo morar.

Reconocer el proceso habitacional desde el espacio personal apropiado por la comunidad LGBTI víctima del desplazamiento forzado en el departamento del Quindío.

Comprender las relaciones mutuales en el espacio público desde la alteridad de la comunidad LGBTI víctima del desplazamiento forzado en el departamento del Quindío.

Interpretar el proceso de trasformación territorial desde la alteridad de la comunidad LGBTI víctima del desplazamiento forzado en el departamento del Quindío.

Observación de campo durante 6 meses.

Cartografía social: tres talleres (mujeres trans, hombres gais, mujeres cisgénero lesbianas).

Habitantes

Relato (entrevista): tres entrevistas (mujeres trans, hombres gais, mujeres cisgénero lesbianas).

Observación de campo durante 6 meses.

Cartografía social: tres talleres (mujeres trans, hombres gais, mujeres cisgénero lesbianas).

Habitantes

Relato (entrevista): tres entrevistas (mujeres trans, hombres gais, mujeres cisgénero lesbianas).

Observación de campo durante 6 meses.

Cartografía social: tres talleres (mujeres trans, hombres gais, mujeres cisgénero lesbianas).

Habitantes Relato (entrevista): tres entrevistas (mujeres trans, hombres gais, mujeres cisgénero lesbianas).

Matriz de categorías desde la proxémica: espacio íntimo, personal $\mathrm{y}$ público.
Relaciones mutuales en el territorio 


\section{Resultados}

\section{Espacio corporal e íntimo}

Uno de los hallazgos en relación a la transformación del primer territorio-el cuerpo-está relacionado con la identidad de género, la expresión del mismo y la orientación sexual.

Mi cuerpo se ha transformado bastante, bastante, bastante, porque pues la verdad, siempre pues con mi versión femenina, y aquí empecé mi proceso de transformación a chica trans, lo que hace que llegué a este territorio, ya venía con unos antecedentes, ya venía femenina, pero mi hormonización comenzó cuando volví a mi pueblo natal. (Mujer transgénero, comunicación personal, 10.02.2019)

Se evidencia que el hecho victimizante se convierte en el detonante para iniciar una nueva vida, donde los miembros de la comunidad LGBTI se sienten libres en relación a su lenguaje corporal y a su manera de relacionarse con su entorno, el cual, muchas veces, está limitado, entre otras variables, por el miedo a la opinión de su núcleo más cercano.

Esta situación de reconocimiento de su ser, de su cuerpo, determina una visión positiva en el arribo al nuevo territorio. De acuerdo a los testimonios:

Todo [marcas del antiguo territorio], yo lo defino como... siempre que hablo de mi tierra y lo comparo con el Quindío, yo le hago una analogía, como el amor de madre y el amor de pareja, a mi tierra le debo todo, allá nací, tengo los recuerdos de mi niñez, tengo esos recuerdos de nostalgia. (Hombre gay, comunicación personal, 10.02.2019)

Los nuevos habitantes generan un sentido de apropiación por el territorio que les permite sentirlo suyo, una construcción emocional que facilita la relación simbiótica entre quien ha llegado y el lugar que lo recibe; es el inicio de la transformación a través de la interculturalidad, del diálogo constante en la tensión entre el recuerdo y el momento.

Las marcas que me han dejado mi nuevo territorio son el haber avanzado o evolucionado. No hace mucho... pongamos por ahí aproximadamente 2 años, he crecido mucho más como persona, yo llegué aquí al Quindío en el año 2000, 2002, 2003, pero ya vine a posicionarme aquí en el Quindío en el 2003, pero fueron unos años de mucha frustración, unos años muy duros, y más que todo cuando uno es una persona sobreviviente de la guerra con una orientación sexual diversa, no común como de toda la población, es muy distinto cuando uno sufre el conflicto armado y ser una mujer cisgénero, a ser 
una persona cisgénero y lesbiana, siempre va a haber mucha más victimización. (Mujer cisgénero lesbiana, comunicación personal, 13.02.2019)

El proceso de transformación territorial se da en la complejidad, en el encuentro del ser que llega con otras realidades, las cuales deben adaptarse a su nuevo vivir. La orientación sexual, la identidad y expresión de género intensifican el hecho victimizante; las personas de la comunidad LGBTI no solo se encuentran afectadas por la violencia directa causada por los actores del conflicto, sino también por la violencia estructural y cultural que promueve su discriminación, desigualdad y limita sus posibilidades en la reconstrucción de su espacio vital.

\begin{abstract}
Algo que yo perdí en mi antiguo territorio es mi dignidad como mujer. ¿Por qué yo digo que mi dignidad como mujer...? Cuando nosotros somos personas de una orientación diversa y nosotros no hemos tenido una relación íntima con un hombre, pero cuando un hombre manosea nuestro cuerpo y se orina encima de nuestro cuerpo... eso se llama violación, violación a los derechos de las mujeres, entonces es algo que a mí me ha marcado por toda la vida. (Mujer cisgénero lesbiana, comunicación personal, 13.02.2019)
\end{abstract}

La violencia hacia las personas de género diverso es, en un trasfondo, una violencia hacia lo femenino, inherente a todas las personas y que, históricamente, en el mundo le ha otorgado un rol de inferioridad. Para Moreno (2008: 24), "la dominación masculina es un esfuerzo sostenido y ejercido por cada hombre sobre lo propio femenino, apuntalándose en parte en los recursos imaginarios, simbólicos y reales de su colectividad, y en parte en los propios recursos psíquicos". Hay una perspectiva, desde lo cultural, de rechazo a la feminidad, que intensifica y permite que se dé lugar a las demás expresiones de violencia, directa y estructural:

Además del consenso del carácter relacional e histórico del concepto de género, la perspectiva de género se interesa por explicar cómo las relaciones de poder inscritas desde muy temprano en la experiencia del sujeto se expresan en las relaciones sociales y los desequilibrios de las mismas. Así, esta perspectiva concibe la violencia contra las mujeres como un abuso de poder en una estructura social que favorece que los hombres agredan a las mujeres y que privilegia los elementos masculinos sobre los femeninos. (Gómez; Murad; Calderón, 2014: 21)

El cuerpo es el instrumento de expresión de los sentires, los cuales son constituidos por los recuerdos y sucesos que han dejado huella en este primer territorio, lo corporal. Estos sentires frecuentemente están cargados de los recuerdos de violencia históricamente intensificada en la comunidad LGBTI. Según un testimonio: 
Se me hace muy difícil la felicidad, porque yo siempre he dicho que no soy una persona o una mujer plenamente feliz, es algo que a mí se me dificulta muchísimo poderlo expresar, poderlo expresar de una manera amplia, porque estoy muy marcada, marcada supermarcada por la guerra, supermarcada por la sociedad, por la discriminación, por los recuerdos y los fantasmas. (Mujer cisgénero lesbiana, comunicación personal, 13.02.2019)

\section{Espacio personal}

El espacio personal se constituye como el espacio del encuentro con ellos mismos, con su sexualidad; el lugar donde se puede ser lo que la sociedad más oculta: la afectividad y el sexo entre miembros LGBTI; es el refugio. Se evidencia un profundo sentido de pertenencia y territorialidad, potencializado por el hecho de que este lugar les ha permitido tener una nueva oportunidad, la cual es fruto de su esfuerzo cotidiano.

Mi casa es mi territorio, es algo muy íntimo, o sea, es mío, es algo muy sagrado, es muy poca la persona que yo llevo a mi casa, obviamente aparte de un amante. La vida me ha enseñado a no llevar gente a mi casa. (Mujer transgénero, comunicación personal, 10.02.2019)

El nuevo territorio propicia también la construcción de nuevas relaciones personales, se constituyen familias que evidencian las nuevas formas de habitar desde la diversidad y deja ver cómo los lazos familiares se entraman a partir de los sentires y no meramente desde lo reproductivo y biológico.

Yo tengo una familia que me adoptó hace mucho tiempo, una familia de amigos, y esa familia de amigos tiene... [silencio], hay tres señoras, muy cercano a una de ellas, entonces cuando llegué a la casa, la niña de ellos estaba muy pequeñita, entonces ella me adoptó como su hermano, y las tres siempre han estado en función de protegerme, aun cuando estoy grande. (Hombre gay, comunicación personal, 10.02.2019)

Sí... yo recuerdo algo muy grande, para mí fue grande, y siento que me marcó, cuando nosotros hicimos... como una especie de seriado o teatro, lo hicimos en Manizales, porque nunca había tenido una familia, como la que sentía... tenía en ese momento, tener el amor, el acompañamiento de un niño, porque pues yo prácticamente me crie con niños, pero los niños fueron en el conflicto, ien la guerra! Entonces, llegar a la edad que yo tengo, nunca había compartido de adulta con un niño pequeño, un niño que me estaba dando mucho cariño, entonces para mí eso fue algo muy placentero, algo que recuerdo con mucho cariño. (Mujer cisgénero lesbiana, comunicación personal, 13.02.2019) 
Otro de los hallazgos está relacionado con la soledad, pues es reiterativo el temor a unas vidas solas, en parte por una sociedad heteroaconductada, la cual ha limitado la posibilidad de crianza, los proyectos comunes que fortalecen las relaciones íntimas y la oportunidad de la contribución generacional a través de la familia.

\section{Espacio público}

En el espacio público se evidencia que los miembros de la comunidad LGBTI no pueden expresar su afectividad y orientación sexual de manera libre, motivo por el cual se relacionan en espacios de menos uso por las demás personas (en este caso, guaduales o zonas verdes de poca concurrencia): "todo Génova tiene recuerdos significativos, el rastrojo, todo... las vivencias, las arrastradas... jTodo!" (mujer transgénero, comunicación personal, 10.02.2019). Esto potencia la vulnerabilidad de las personas, al encontrar en espacios poco seguros, donde se dan actividades como la venta y consumo de drogas, robo, etc., su lugar de encuentro y de libre expresión.

Me siento libre cuando camino en medio de un guadual, cuando me voy a pie de Armenia a Hojas Anchas y paso por las vías que hay guaduales, siento libertad, me siento libre cuando puedo rumbear, y puedo rumbear por ejemplo con otro hombre, también en mi espacio y con la familia que comparto. (Hombre gay, comunicación personal, 10.02.2019)

Las instituciones públicas, religiosas y gubernamentales son las que, paradójicamente, generan sensación de vulnerabilidad y rechazo:

¿En qué lugar siento miedo...? Le tengo miedo es a la policía, ¡hijueputas...! ¡Me siento vulnerada y rechazada por la policía, por la policía, aquí y en todo lado, para que lo dejes en claro por favor...! El lugar que menos me gusta es el comando de policía. (Mujer transgénero, comunicación personal, 10.02.2019)

Me siento vulnerada cuando hacen acusaciones fuertes sobre mi persona, cuando son cosas que no son reales, me siento supervulnerada y siento que mis derechos como persona y como mujer cisgénero son pisoteados, y me siento vulnerada y discriminada con las personas de alguna parte de la sociedad, que son personas como retrogradas que tienen una mente muy cerrada y creen que las mujeres cisgénero o lesbianas y más cuando son excombatientes son un problema para la sociedad. (Mujer cisgénero lesbiana, comunicación personal, 13.02.2019)

La violencia cultural hacia la mujer y lo femenino se intensifica con las nuevas violencias que se tejen, en el pos acuerdo, las víctimas y los excombatientes; en una 
sociedad polarizada, la comprensión del otro como igual en derechos se complejiza; la falta de empatía por el otro, por sus motivantes, sus razones y, en general, por su ser, ha dificultado y llevado a la aparición de nuevas formas de violencia estructural en Colombia.

También se evidencia una preocupación por las políticas públicas y la visión del Gobierno nacional en torno al libre desarrollo de la personalidad y la garantía de los derechos de las personas LGBTI. En los territorios, es necesario fortalecer las instituciones en atención a personas que hacen parte de este sector social, atención médica, atención en caso de violencia y acompañamiento psicológico, entre otros.

Creo que, en lo religioso, o sea, en el espacio religioso, uno siempre se va a sentir vulnerado, porque hay una formación donde la gente siempre cree que ser gay, ser parte de la comunidad LGBTI, es ser enfermo; entonces uno siempre se va a sentir vulnerado, el Estado también, el gobierno, yo tengo una visión más política. Por ejemplo, en un plan de desarrollo como el de Duque: jvulnerado!, porque quien está adelantando esas propuestas, que de alguna manera van en defensa a los derechos humanos de las comunidades, de las minorías, que lo esté liderando un partido político como Colombia Libre y Justa, que tiene un sesgo religioso, uno siempre va a ver vulnerado sus derechos y el desarrollo de su personalidad, personas políticamente ligadas a la religión. (Hombre gay, comunicación personal, 10.02.2019)

Aun en el nuevo territorio se reconocen miedos y sentimientos por el lugar natal, estos hacen parte de los recuerdos que traen los nuevos habitantes y de la constitución de las personalidades de cada miembro:

Siento miedo en mi tierra, cuando en la noche... Mi niñez estuvo marcada, mis últimos años estuvieron marcados de guerrilla, paramilitares y ejército, y en mi tierra los paramilitares siempre manejaban motos de alto cilindraje, y en mi tierra, en Puerto Asís, hay espacios donde no hay alumbrado público, entonces siento miedo cuando puedo sentir un vehículo o una moto de cilindraje alto, cuando voy a mi tierra. (Hombre gay, comunicación personal, 10.02.2019)

Otro hallazgo es el reconocer su papel en la construcción de una sociedad más justa y equitativa. Su rol dentro de la ciudad ha permitido la comprensión de la diversidad en su entorno inmediato (como se muestra en la Figura 2); su personalidad y su existencia han marcado las comunidades del territorio que habitan.

Mi personalidad es la marca que yo le he dejado a este territorio, como gay, como homosexual, o como marica que era en ese momento, siempre he sido yo, siempre he sido marcada yo, siempre he sido yo y siempre han respetado esa parte mía, a pesar de ser un pueblo conservador. (Mujer transgénero, comunicación personal, 10.02.2019) 
Mi liderazgo por mi población, por mi comunidad LGBTI, el ser la primera mujer trans que hay en Génova, Quindío, que siempre me he impuesto, me he impuesto como tal, la gente ha ido aceptando, se ha ido abriendo, aceptando, asimilando, entonces yo pienso que he ganado un territorio o un espacio muy grande en la comunidad como tal. (Mujer transgénero, comunicación personal, 10.02.2019)

FIGURA 2 Mapeo social cuerpo-territorio participantes, mujer transgénero y hombre gay
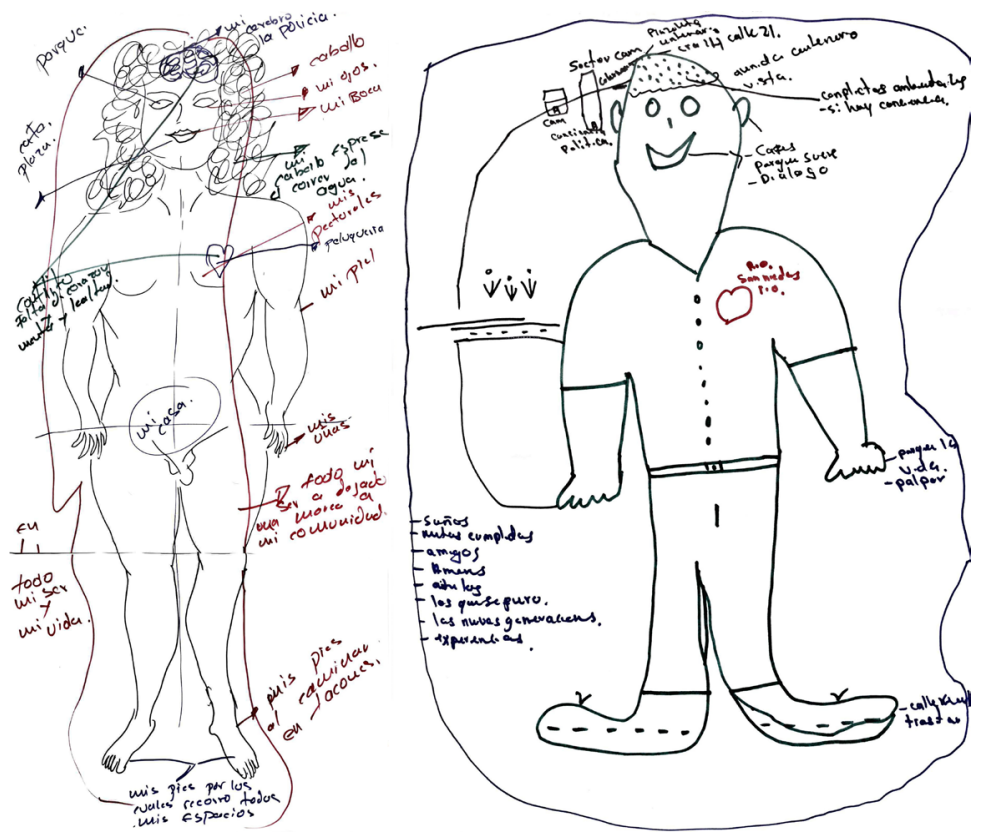

Fuente: taller realizado por mujer transgénero y hombre gay.

El visibilizarse como miembro del grupo social LGBTI complejiza el desarrollo personal de quienes han sido víctimas del conflicto social y armado; sin embargo, la constante contribución desde sus escenarios de actuación y la búsqueda de la mejora de las condiciones de vida para otras personas que pertenecen a este mismo grupo evidencia no solo la satisfacción personal, sino también la autorrealización y reconocimiento por parte de su círculo vital.

Los recorridos más significativos que yo hago en la ciudad... cuando voy a la oficina, para mí me llena muchísimo, me llena muchísimo porque antes... los primeros mo- 
mentos en que yo llegue a trabajar a la Gobernación de[1] Quindío sufrí mucho el tema de la discriminación, por mi orientación, pero poco a poco me fui haciendo querer de mis compañeros, y yo ya siento que estoy en mi confort, y eso a mí me llena mucho, cuando yo tengo que ir a la oficina, encontrarme con mis compañeros, porque me dan ya mucho respeto, siento que me quieren muchísimo, para mí eso es muy placentero. (Mujer cisgénero lesbiana, comunicación personal, 13.02.2019)

El territorio ha marcado a quienes habitan, pero, a su vez, estos marcan el territorio con sus recuerdos y sentires. La comunidad LGBTI evidencia una importante participación en las dinámicas de la ciudad, en cuanto a su manera de intervenir, de involucrarse con el sector productivo y en la lucha por la igualdad en derechos (ver Figura 3).

FIGURA 3 | Mapeo social cuerpo-territorio mujer cisgénero lesbiana

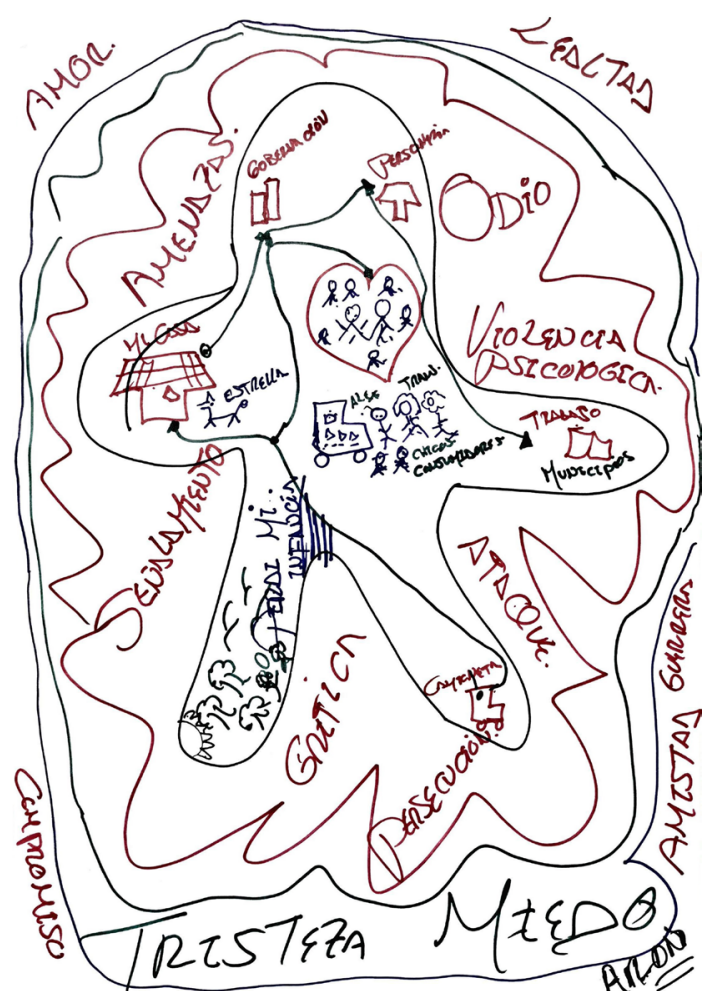

Fuente: taller realizado por mujer cisgénero lesbiana. 


\section{Conclusiones}

Las personas miembros del sector social LGBTI, después del hecho victimizante que concluye en el destierro, abandono de sus lugares natales y posterior arribo a un nuevo lugar que les brinda la oportunidad de desplegar sus capacidades y libertades, transforman el territorio, contribuyendo a su desarrollo y aportando, desde sus talentos diversos, a consolidar una sociedad más justa donde todos podamos tener acceso a los mismos derechos.

Esta transformación evidencia una relación simbiótica, donde el habitante es transformado, pero, a su vez, muta su entorno, lo marca y recibe marcas. El Quindío, como departamento receptor, tiene un potencial valor en cuanto a la interculturalidad que en él se da, así como en el talento diverso que habita su territorio, una manera diferente de habitar y ser, desde relaciones más abiertas, equitativas y humanas. Es necesario promover la formación de personas del grupo social LGBTI y su capacitación en los diferentes niveles de escolaridad, de manera que se dé cumplimiento a políticas de educación sin discriminación; así como impulsar iniciativas de talento diverso donde se reconozcan las capacidades particulares de estas comunidades y se potencie el ofrecimiento de servicios para la misma comunidad como mercado emergente.

Paradójicamente, las instituciones públicas y religiosas, que tienen como objeto velar por el bienestar de los ciudadanos, son las que generan más resistencia y discriminación, de acuerdo con la percepción de los miembros del grupo social LGB$\mathrm{TI}$; esto evidencia la urgente necesidad de fortalecimiento de la institucionalidad, donde el gobierno debe ser garante del cumplimiento de los derechos de todos los miembros del Estado, pues todos somos iguales en derechos y nuestra diversidad obliga a que se dé un enfoque diferencial real en los territorios. Derechos como la crianza, los proyectos comunes que fortalecen las relaciones íntimas y la contribución generacional a través de la familia han estado ligados, exclusivamente, a la naturaleza binaria (hombre y mujer), reproductiva y genética.

Lo femenino sigue siendo objeto de violencia cultural en Colombia, haciendo necesaria una trasformación estructural, que solo podrá ser posible con educación y políticas públicas eficaces, donde se reconozca la histórica cultura de violencia y los hechos victimizantes que se han ejercido sobre las mujeres y cualquier expresión de lo femenino (presente en todos), un rechazo que actualmente se evidencia en la desigualdad de condiciones sociales y económicas, las altas cifras de violencia directa y el no disfrute pleno de los derechos como ciudadanos.

Nuestra sociedad obedece a estructuras jerárquicas donde la normalidad es dominante y es asociada solo a los comportamientos heterosexuales, incluso desde el núcleo familiar y la escuela se establecen controles a través de la violencia (directa, 
estructural o cultural) que refuerzan este estado de subordinación de los miembros del grupo social LGBTI, y que trascienden a escenarios como el conflicto social y armado en Colombia, que se recrudece y es más agresivo cuando quienes lo viven no cumplen con los parámetros normalizados.

El conflicto social y armado en Colombia, que experimenta una etapa de posacuerdos de paz, ha propiciado el surgir de nuevas violencias estructurales en nuestra sociedad: una violencia hacia las personas que han participado directamente de él, víctimas y excombatientes, que expone la ausencia de una verdadera reconciliación de la sociedad civil. Los territorios deben cambiar el proyecto de la venganza por el proyecto del futuro común, comprendiendo lo que cada integrante de una sociedad, como ser único y diverso, puede contribuir al desarrollo los mismos.

En la relación simbiótica entre la comunidad LGBTI y su territorio, se genera un acto de coapropiación, donde el espacio físico se hace territorio en la medida que se habita, se carga de emociones; es parte de la naturaleza del hombre y la mujer ser históricos, pero también ser espaciantes, pues el espacio constituye a los sujetos y los sujetos al espacio. El habitar implica la plena consciencia de esto y la intervención activa en la construcción del lugar que se ocupa, mientras las dinámicas sociales afirman la apropiación del sujeto por su territorio, y es allí donde interviene una producción histórica, que le identifica y constituye una manera de existir en el mundo, una existencia que avanza hacia un territorio más justo y en el cual se garanticen las libertades de cada individuo. La mutación territorial se da en la lucha que hoy hacen las personas de la comunidad LGBTI, invisibilizadas o desvalorizadas por su orientación sexual, identidad o expresión de género (el mundo huérfano), una lucha desde la resiliencia en la construcción de una nueva vida, del reconstruirse después del destierro, la osadía de exponer sus logros, su contribución al desarrollo como humanidad y la representación de unos cuantos que aún temen por ser identificados en una sociedad heteroaconductada.

\section{Referencias}

Alvarado, Sara; Ospina, María Camila; Sánchez, María Cristina (2016). Hermenéutica e investigación social: narrativas generativas de paz, democracia y reconciliación. Revista Latinoamericana de Ciencias Sociales, Niñez y Juventud, 14(2), 987-999.

Ana González expone su obra en Suecia (17 de junio de 2016). El Nuevo Siglo. Recuperado de https://www.elnuevosiglo.com.co/articulos/6-2016-ana-gonz\%C3\%A1lez-expone-suobra-en-suecia 
Ángel-Pérez, Darío (2011). La hermenéutica y los métodos de investigación en ciencias sociales. Estudios de Filosofia, 44, 7. Recuperado de http://www.scielo.org.co/scielo.php?script=sci_ arttext\&pid=So121-36282011000200002\&lng=en\&tlng=es

Ardelean, Ciprián (2001). Por una nueva proxémica antropológica. Boletín de Antropología Americana, 37, 7-34. Recuperado de https://search.proquest.com/openview/f59e $7727 \mathrm{df8}$ 3 f625c51f6936cd6ofo62/1?pq-origsite $=$ gscholar $\& \mathrm{cbl}=32759$

Bustos-Velazco, Edier; Molina-Andrade, Adiela (octubre, 2012). El concepto de territorio: una totalidad o una idea a partir de lo multicultural. Trabajo presentado en XI INTI International Conference La Plata, Argentina. Recuperado de http://www.memoria.fahce.unlp.edu.ar/ trab_eventos/ev.2639/ev.2639.pdf

Caputo, Giuseppe (2016). Un mundo huérfano. Bogotá: Penguin Random House.

Cardona-Cuervo, Jimena (2016). La construcción de los derechos del grupo social transgénero. Entramado, 12(2), 84-95. https://dx.doi.org/10.18041/entramado.2016v12n2.242O2

Centro Nacional de Memoria Histórica (2015). Aniquilar la diferencia. Lesbianas, gays, bisexuales $y$ transgeneristas en el marco del conflicto armado colombiano. Bogotá: CNMH/UARIV/ USAID/OIM.

Colombia Diversa (2017). Vivir bajo sospecha. Estudios de caso: personas LGBT víctimas del conflicto armado en Vistahermosa y San Onofre. Recuperado de http://www.colombiadiversa.org/ conflictoarmado-lgbt/documentos/vivir\%2obaja\%2osospecha.pdf

Colombia Diversa; Caribe Afirmativo (2018). La discriminación, una guerra que no termina. Informe de derechos humanos de personas lesbianas, gays, bisexuales y trans. Colombia 2017. Recuperado de https://colombiadiversa.org/colombiadiversa2016/wp-content/ uploads/2018/o7/A-045O_OS_baja-Informe-DDH.pdf

Dietz, Gunther (2017). Interculturalidad: una aproximación antropológica. Perfiles Educativos, 39(156), 192-207. Recuperado de https://www.redalyc.org/articulo.oa?id=13250923012

Eito, Antonio; Gómez, Juan David (2013). El concepto de comunidad y trabajo social. Revista Espacios Transnacionales, 1. Recuperado de http://www.espaciostransnacionales.org/ conceptos/conceptotrabajosocial/

Fundación Cultural Waja (23 de junio de 2012). ¿Cuánto cuesta ser?-Ladyzunga [Video]. Recuperado de https://www.youtube.com/watch?v=6xo5lzBiu8o

Galtung, Johan (2016). La violencia: cultural, estructural y directa. Cuadernos de Estrategia, 183, 147-168. Recuperado de https://dialnet.unirioja.es/servlet/articulo?codigo $=5832797$

Gobernación del Quindío (2016).Plan de Desarrollo Departamental2016-2019 “En defensa delbien común”. Recuperado de https://www.quindio.gov.co/plan-de-desarrollo-departamental/ plan-de-desarrollo-2016-2019-en-defensa-del-bien-comun 
Gobierno de Colombia; Fuerzas Armadas Revolucionarias de Colombia (2016). Acuerdofinalpara laterminación del conflictoyla construcción deunapazestableyduradera. Recuperadodehttps:// www.cancilleria.gov.co/sites/default/files/Fotos2016/12.11_1.2016nuevoacuerdofinal.pdf

Gómez, Claudia; Murad, Rocío; Calderón, María Cristina (2014). Historias de violencia, roles, prácticas y discursos legitimadores. Violencia contra las mujeres en Colombia 2000-2010. Bogotá: Profamilia.

González, Mabel (2006). Desterrados: el desplazamiento forzado sigue aumentando en Colombia. Recuperado de https://ebookcentral-proquest-com.bdigital.sena.edu.co

Henao-Delgado, Hernán (1999). Los desplazados: nuevos nómadas. Nómadas, 10, 62-76. Recuperado de http://www.redalyc.org/articulo.oa?id=105114274006

Hidalgo, Roxana (2006). La otredad en América Latina: etnicidad, pobreza y feminidad. Recuperado de https://ebookcentral-proquest-com.bdigital.sena.edu.co

Jiménez, David (2017). Investigación cualitativa. Bogotá: Universidad La Salle.

Molina, Astrid (2018). Territorio, lugares y salud: redimensionar lo espacial en salud pública. Cadernos de Saúde Pública, 34(1). https://dx.doi.org/10.1590/0102-311x00075117

Molina, Miriam; Calzadilla, Marisol (2010). El mutualismo social, la diversidad y complejidad en la red intersectorial. En: Memorias del programa cientifico universidad 2010. Recuperado de https://ebookcentral-proquest-com.bdigital.sena.edu.co

Moreno, Fredy (2008). La producción de masculinidad: entre la dominación y el rechazo de lo femenino. Boletín de Antropología, 22(39), 11-32. Recuperado de https://www.redalyc. org/pdf/557/557119080o1.pdf

Pulecio, Mauricio (2015). Cuando Oliver se dio un beso con otro niño, con su mejor amigo, Dick: lenguajes literarios y lenguajes violentos dirigidos a jóvenes LGBTQ en el sistema escolar. Revista CS, 15, 17-39. https://doi.org/10.18046/recs.115.1986

Raffestin, Claude (2012). Space, Territory, and Territoriality. Environment and Planning D: Society and Space, 30, 121-141. https://doi.org/10.1068/d21311

Red Nacional de Información (2018). Desplazamiento-Personas. Recuperado de https://cifras. unidadvictimas.gov.co/Home/Desplazamiento

Rodrígues, Vera (2013). Simbioses de um conflito. Desplazamiento e identidade negra na Colômbia. Revista CS, 12, 129-156. https://dx.doi.org/10.18046/recs.i12.1679

Smith, Dan (2002). Tendencias y causas del conflicto armado. Recuperado de https://berghoffoundation.org/library/tendencias-y-causas-del-conflicto-armado

Unidad para la atención y reparación integral a las víctimas (2018). Registro único de víctimas. Recuperado de https://www.unidadvictimas.gov.co/es/registro-unico-de-victimasruv/37394 